كاربرد سيستمهاى تكاملى در تعيين ضريب دبى سرريزهاى كنخرهاى مثلثى

مهدى ماجدى اصل "* و مهدى فولادى يناه؟

(تاريخ دريافت: س M

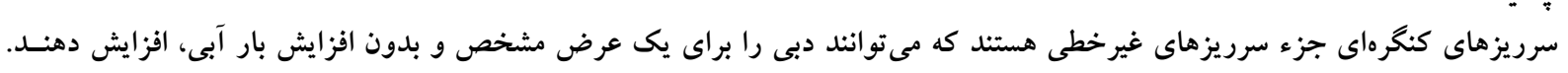

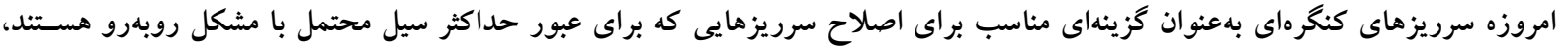

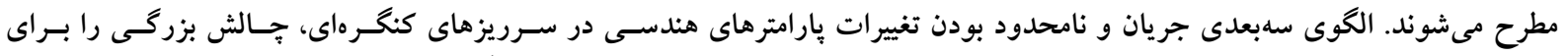

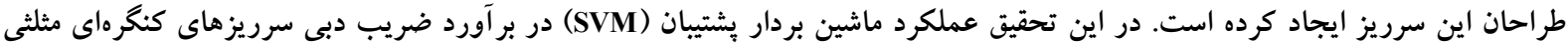

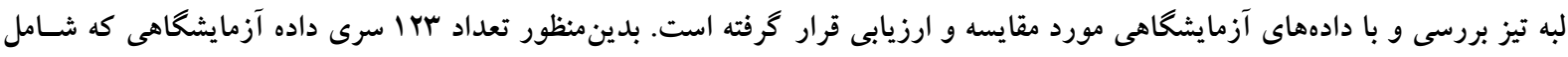

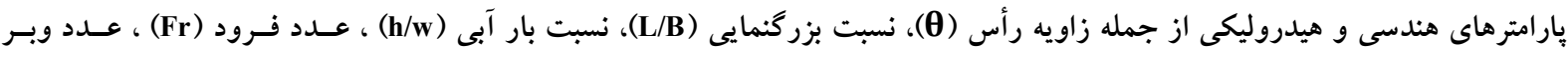

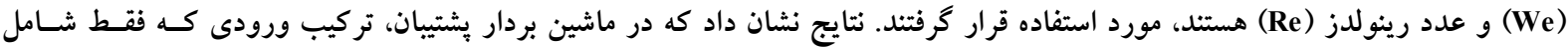

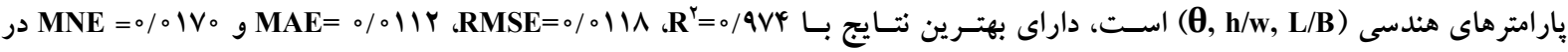

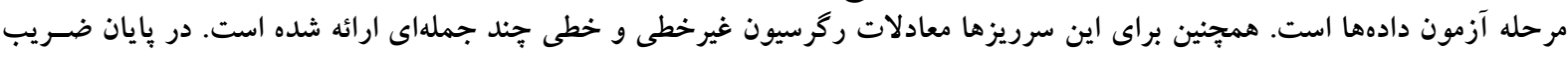

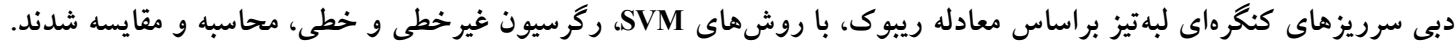

وازمهاى كليدى: سر ريز كنكرهاى مثلثى، ماشين بردار بشتيبان، معادله Rehbock، زاويه رأس سرريز

ا. كروه مهندسى عمر ان، دانشكده فنى و مهندسى، دانشكاه مر اغه، مراغه

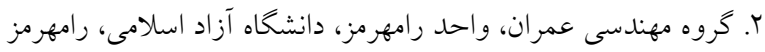

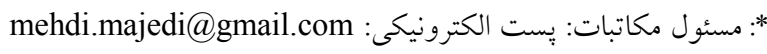


محمدى (4) سرريزهاى زيخزاخـى بــا بـلان قوسى را بررسى

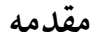

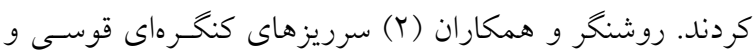

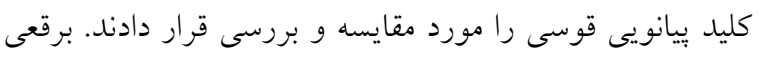

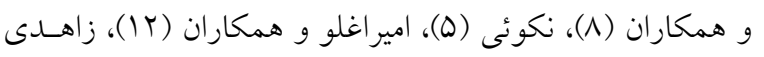

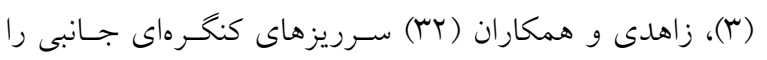

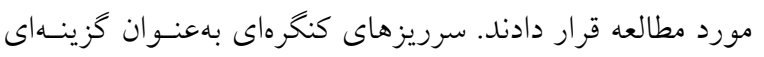

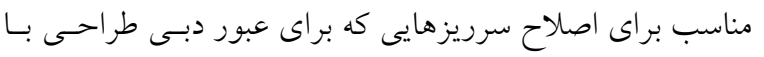

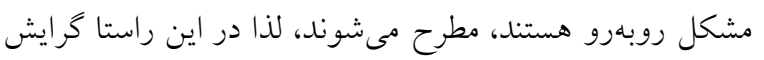

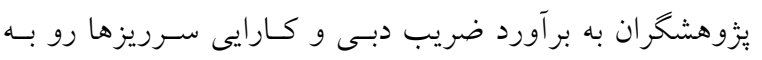

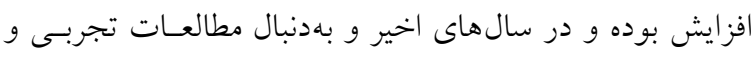

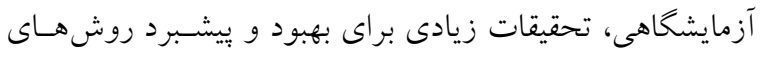

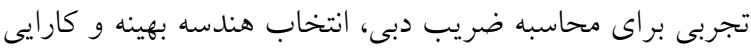

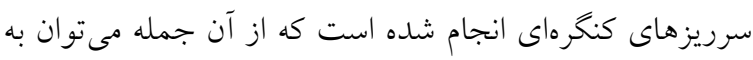
روش هاى محاسبات نـرم كـه داده محسور هستـند اشــاره كـرد.

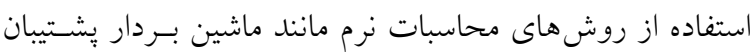

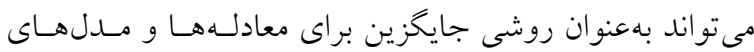
تجربى بهحساب آيد و در دهلهاى اخير تحولى عظيم در مسائل

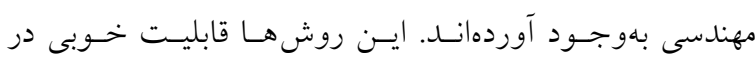

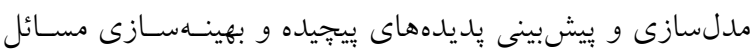
مهندسى از خود نشان دادهاند.

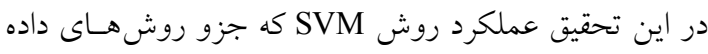

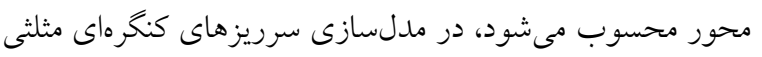

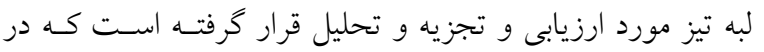

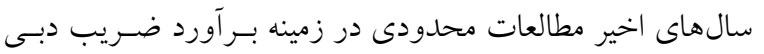

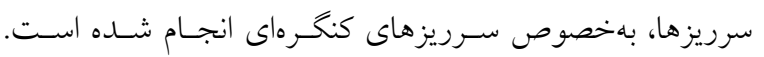

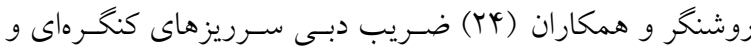

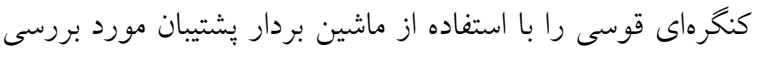

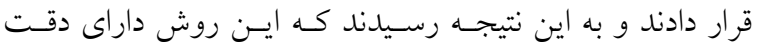

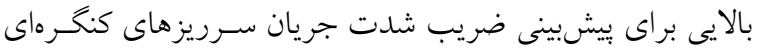

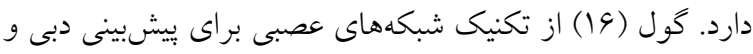

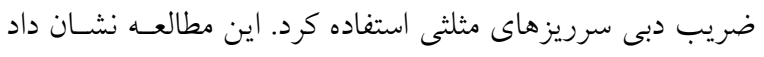

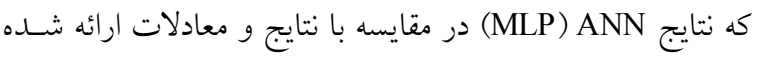
سرريزهاى كنخرهاى يكى از مهمترين سازهايى هستند كه براى

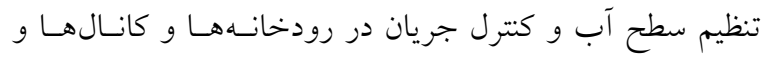

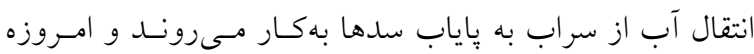

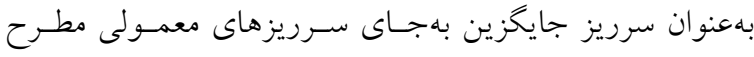

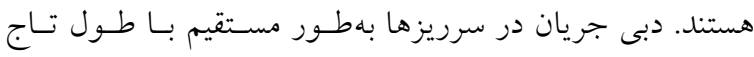
سرريز متناسب است. در صورتى كه عرض كانال يا مخزنى كـهـ

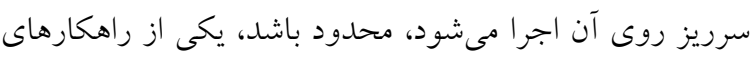

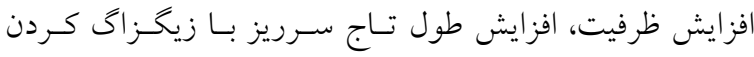

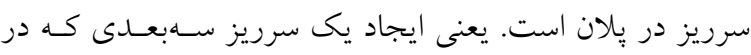

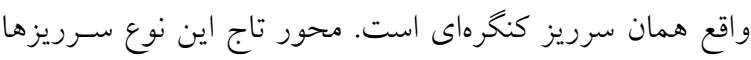

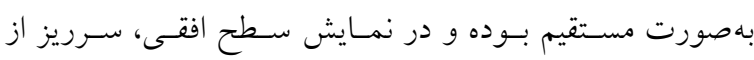

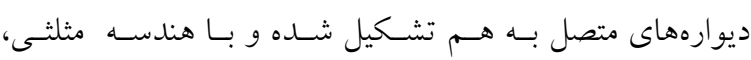

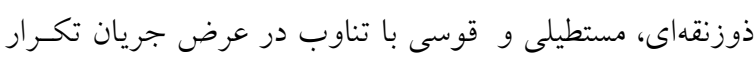

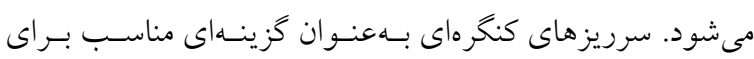

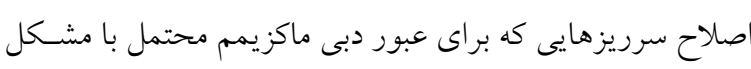

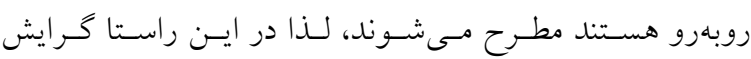

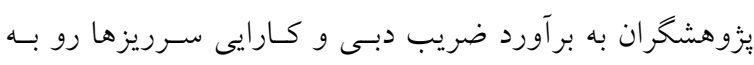

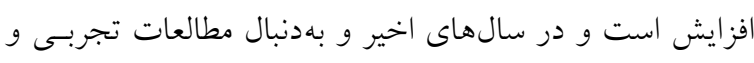

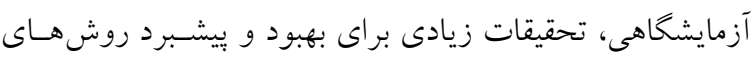

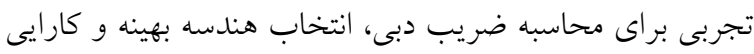

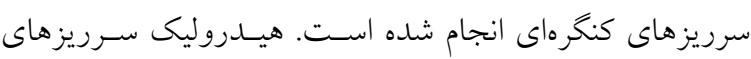

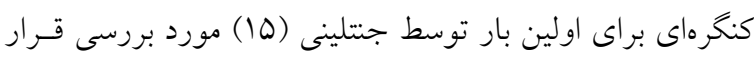

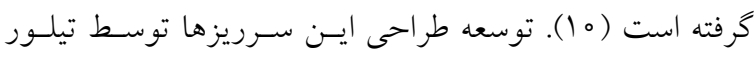

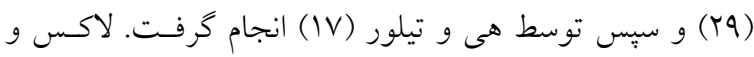

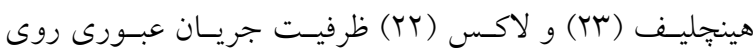

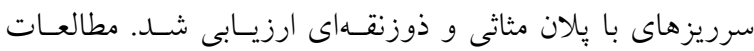

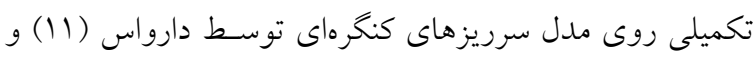

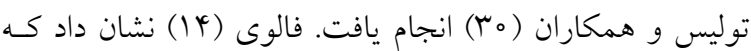

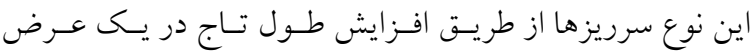

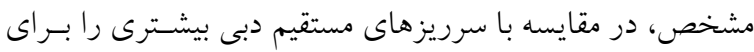

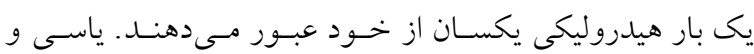


غيرخطى براى ضريب دبى اين سرريزها ارائه شـده و در پِايـان براى زواياى مختلف رأسها، روابطى بر اساس ريبوى بيشئهنهاد

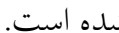

\section{معادله دبى و پِارامترهاى سرريزهاى كنخرهاى}

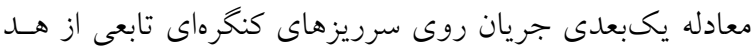

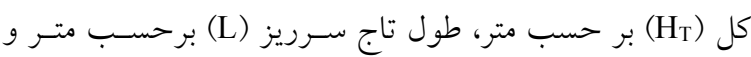

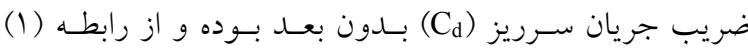
بهدست مى آيد و دبى جريان برحسب متر مكعب بر ثانيه اسـت

$\mathrm{Q}=\frac{\mathrm{r}}{\mathrm{r}} \mathrm{C}_{\mathrm{d}} \mathrm{LH}_{T}^{\mathrm{V} / \Delta} \sqrt{\mathrm{rg}}$

با استفاده از روش تحليل ابعادى و با درنظر گرفتن بارامترهـاى هندسى، سينماتيكى و ديناميكى، بارامترهاى مؤثر بر ضريب دبى ني

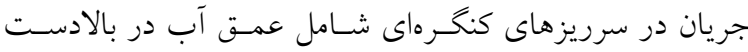

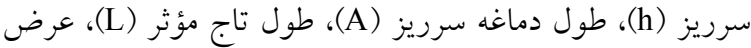
كل كانال (B)، زاويه رأس (ق)، ارتفاع سـرريز (w)، ضـخامت

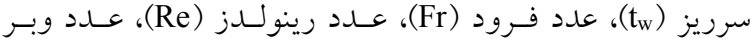
(We)، تعداد سيكلها (Ne)، و شكل تاج سرريز هستند. شكل 1 (N)

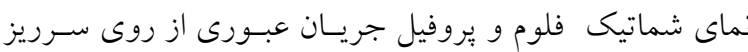

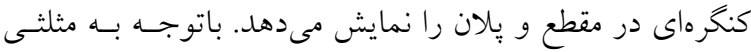
بودن سر ريزها و ثابت بودن ضخامت سرريزها، تعداد سيكلهـا و شكل تاج سـرريز ضـريب دبسى ايسن سـرريزها را مسىتـوان بهورت رابطه (T) ارائه داد.

$\mathrm{C}_{\mathrm{d}}=\mathrm{F}(\mathrm{h} / \mathrm{w}, \theta, \mathrm{L} / \mathrm{B}, \mathrm{Fr}, \mathrm{Re}, \mathrm{We})$

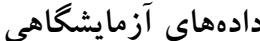

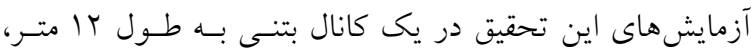

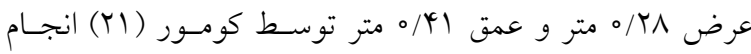

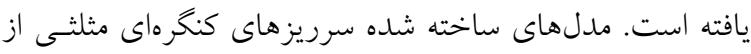
جنس فولادى و لبه تيز بوده و در ال 1 مترى از بالادسـت كانـال

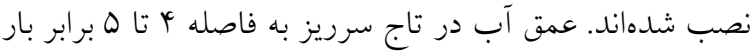

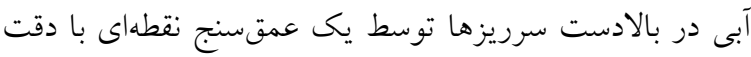

توسط كومور و همكاران (Iا) عملكرد بهترى دارد. جسى و يسو

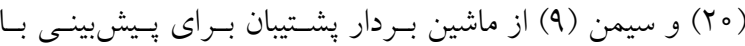

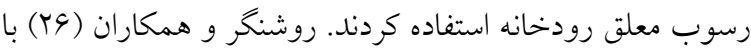

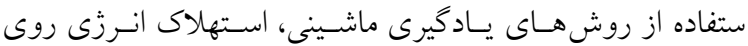

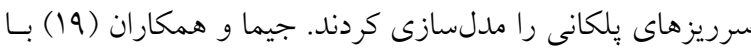

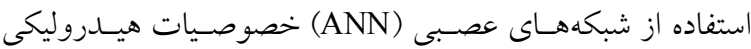

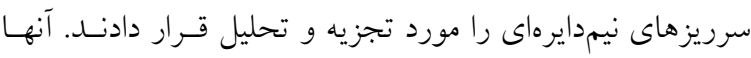

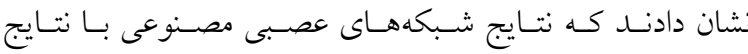

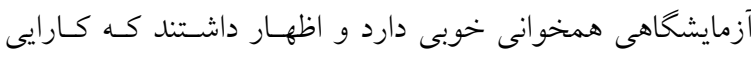
تكنيكهاى ANN در مقايسه با روشهـاى آمـارى بهتـر هسـتند.

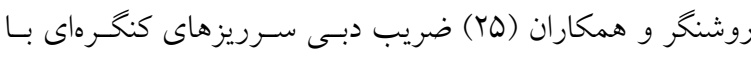

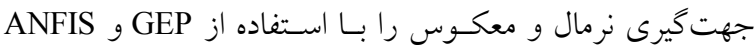

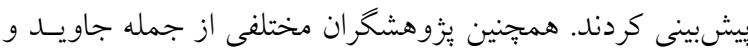

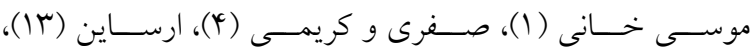

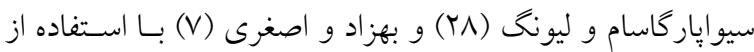
يارامترهاى مختلـف هيـدروليكى و هيـدرولوزى را مـورد يبشيبنى قرار دادند. هدف تحقيق حاضـر، كـاربرد روش ماشسين بردار بشتيبان در بيشيينى ضريب دبى سـرريزهاى كنخـرهاى لبـه

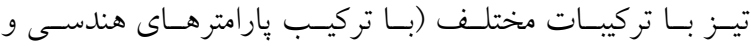
هيدروليكى) و ارائه روابط رخرسيونى خطى و غيرخطى بـراى

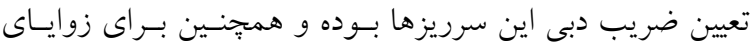
مختلف رأس اين سـرريزها و براسـاس معادله ريبـوك، روابـط

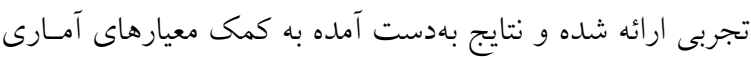
مختلف با روشهاى SVM و كومور (Yl) مورد مقايسه و بررسى بلى

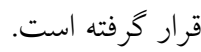

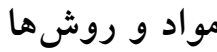
دراين تحقيق براى محاسبه ضريب دبى سرريزهاى كنخرهاى لبه

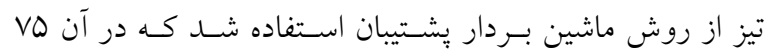

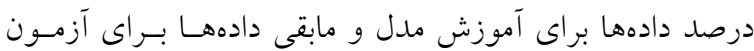

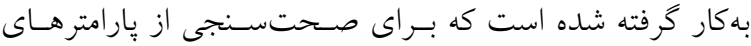

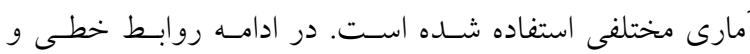




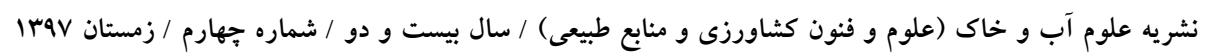

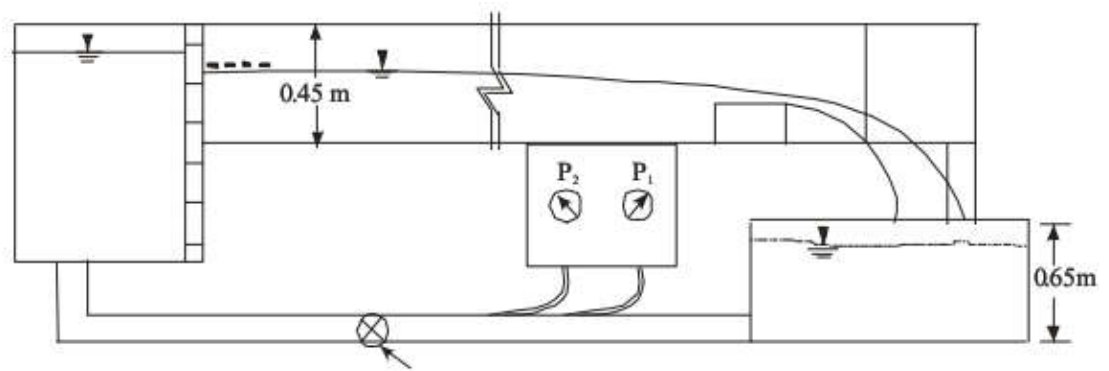

(الف)

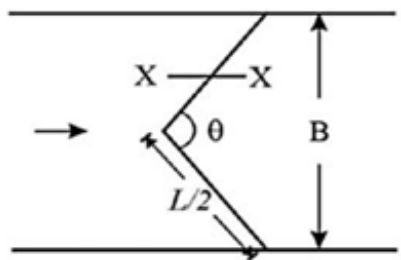

(ج)

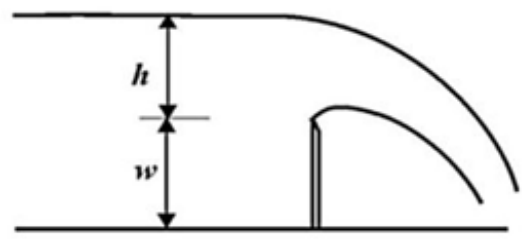

$(ب)$

شكل (. الف) شماتيك فلوم و تجهيزات نصب شده، ب) بروفيل طولى سرريز كنخرهاى و ج) بِلان سرريز كنخرهاى

جدول ا. محدوده دادههاى مورد استفاده در اين تحقيق

\begin{tabular}{|c|c|c|c|c|c|}
\hline تعداد آزمايش & (متر مكعب بر ثانيه) Q & h h & (متر) W & 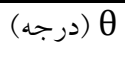 & رديف \\
\hline$r_{0}$ & O/OITO-O/OOT० & O/OHYG-O/00VQ & O/०QYY & $\mu_{0}$ & 1 \\
\hline r & $0 / 0|Y 0-0 / 00 Y|$ & $. / 0 \Delta 90-0 / 01 Y q$ & $0 / 1000$ & 90 & r \\
\hline tr & $0 / 0|Y|-0 / 0010$ & $.09419-0 / 0149$ & $0 / 1 \circ Y q$ & 90 & r \\
\hline ro & $0 / 0|Y Y-0 / 00 Y|$ & $. / 0 V T \Delta-0 / 019 V$ & $0 / 1094$ & Iro & r \\
\hline ro & $0 / 011 r-0 / 0014$ & $0 / 0 V 10-0 / 014 T$ & $\circ / 1 \circ V \Delta$ & 100 & 0 \\
\hline 11 & $0 / 0109-0 / 00 Y T$ & O/OVYY-O/OYKY & $0 / 1000$ & 110 & 9 \\
\hline
\end{tabular}

روشهاى يادگيرى با ناظر هستند كه براى مسـائل طبقـهنــىى، ركرسيون، بيشبينى و سـاير مسـائلى كـه در ايسن حـوزه قـرار مى گيرند، بهكار مىرود. مراحل حل مسائل در ماشينهاى بردار

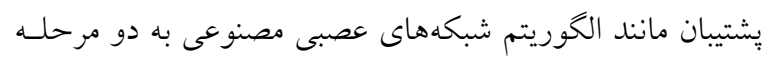
آموزش و تست (صحتسـنجى) تقسـيم مسىشـود. ايسن روش توسط واينيك (آM) بر مبناى نظريه يادكيرى محاسباتى توسـعه يافته است. ماشينهاى بردار يشتيبان بر خلاف ساير روشهـاى هوش مصنوعى به جاى اينكه خطاى محاسباتى را كاهش دهد،

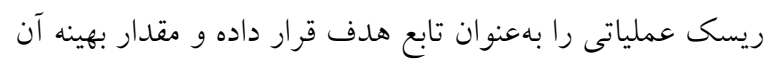
را بهدست مى آورد. SVM قادر اسـت مسـئله را توسـط ترفنـد كرنل به فضاى با ابعاد بيشتر ببرد. در شكل (r- الف) در فضاى

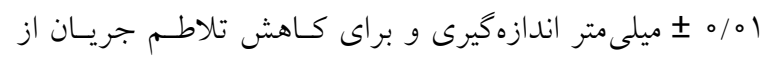

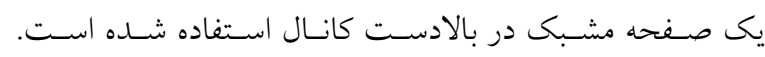

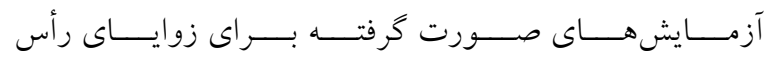

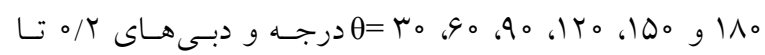

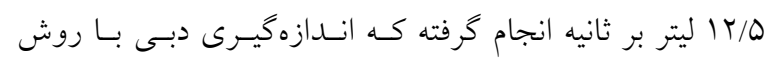

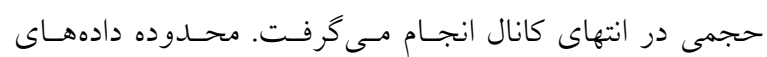
آزمايشخاهى اين تحقيق در جدول آآورده شده است.

ماشين بردار پِشتيبان (SVM)

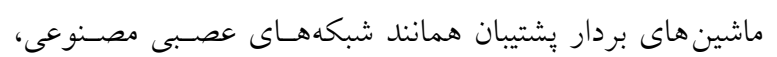
يكى نوع الكوريتم داده محـورى اسـت. ايسن روش دسـتهاى از 


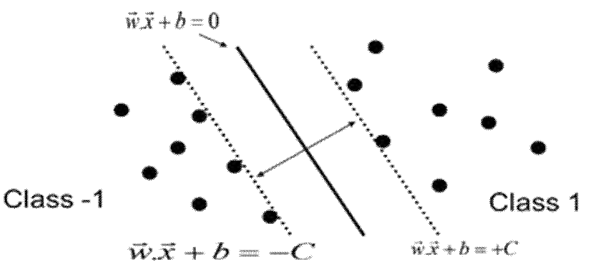

(ب) $\times 2$

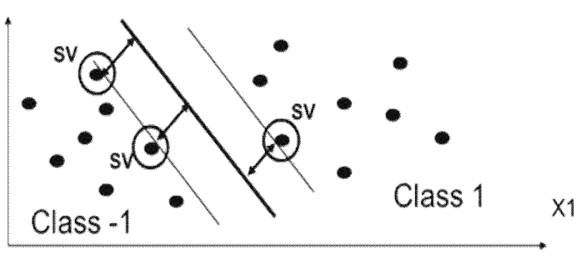

(الف)

شكل r. جداسازى دادهها در: الف (SVM و بردارهاى يشتيبان

$\operatorname{Min} \frac{1}{r}\|\mathrm{~W}\|+C \sum_{\mathrm{i}} \xi_{\mathrm{i}}$

يارامتر C تابع جريمه ناميده مىشود و به نوعى مىشود بيان كرد

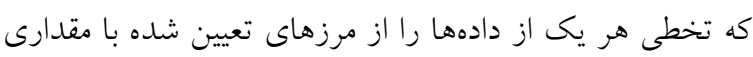

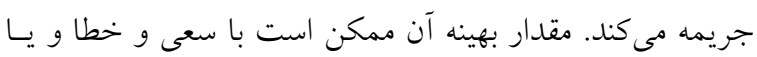
از طريق الخوريتمهاى بهينهسازى بهدست بيايد. در مسائلى كـه دادهها بهصورت خطى تفكيـك يـذير نباشــند، معادلـه صـفحه

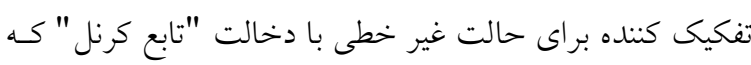
وظيفه نخاشت دادهها از فضاى غيرخطى به خطى را بـر عهـده دارد، حاصل مىشود. در نتيجه معادله تفكيك كننده بـهصـورت

$$
\text { زير تبديل مىشود. }
$$

$\mathrm{w}^{\mathrm{T}} \mathrm{z}+\mathrm{b}=\mathrm{\circ} \rightarrow \mathrm{w}^{\mathrm{T}}(\mathrm{x})+\mathrm{b}=\mathrm{。}$

كه در عبارت فـوق تـابع ب وظيفـه نخاشـت دادههـا از فضـاى غيرخطى به يك فضاى خطى را به عهده دارد. مىتوان براى ايسن تابع يك حالت كلى تر بهصـورت بهوسيله آن بتوان به فضاهاى بييجيدهتر راه يافت. به فرايند مذكور ترفند كرنل مى گويند. توابع كرنل شكلهاى مختلفى دارند و هـر كدام مىتوانند با توجه به طبيعت مسئله كاربرد خاص خودشان را داشته باشند. انواع مختلف تابع كرنـل در جــدول (Y) نشـان داده شـده اسـت. تـابع كرنـل خطى حالـت خاصسى از تـابع كرنـل جناجملهاى است كه از توابع رايج و يركاربرد در مسائل هسـتند. تابع كرنل جند جملهاى در مسائل بيجيجيده مىتواند بسيار مفيـدتر باشد. توابع قوسى (RBF) و كرنل حلقوى (ERBF) معروفترين و يركاربردترين توابع كرنل در مسائل ماشين بردار يشتيبان هستند و در مسائلى مورد استفاده قرار مى گيرند كه هيجخحونه اطلاعىى از نوع دادهها و طبيعت آنها دردسـت نباشـد. مشخصسههـاى مـدل
دو بعدى براى جداسازى دادههاى دو كـلاس، بـىنهايـت خـط وجود دارد. نزديكترين داده آموزشى به صفحه تفكيكى كنتـده بردار يشتيبان ناميده مىشود كه در شـكل (Y- ب) آورده شــده

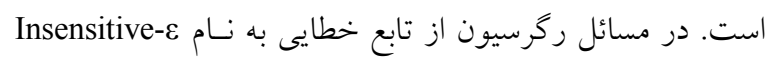

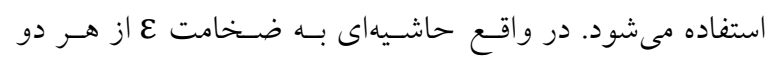
طرف صفحه تفكيك كننده در نظر كرفته مىشود. ناحيه بين دو خط كنارى، ناحيه مجاز براى قرارگيرى دادهها است و هـر داده كه خارج از اين محدوده قرار كيرد به نسـبت تخطى از ناحيـه مجاز، توسط تابع جريمه، جريمه مىشود. بس بهينهترين صفحه تفكيك كنــده، صـفحهاى اسـت كـه داراى ماكزيمم فاصله بين دو كـلاس باشـــ. بـه عبـارت ديخـــ

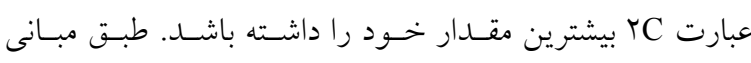
هندسه تحليلى خواهيم داشت: $C=\frac{r}{\|W\|}$

يس مقدار مـاكزيمم C زمـانى حاصـل خو اهـــ شــ كـه |WW كمترين مقدار را داشته باشد.

$\operatorname{Min} \frac{1}{r}\|W\|$

و معادله كلى صفحه بهينه بهصورت زير خواهد بود: $\mathrm{w}^{\mathrm{T}} \mathrm{x}+\mathrm{b}=。$

ممكن است بعضى از داده ها در محدوده تفكيك شــه كـلاس خود قرار نداشته باشند. به عبارت ديخر دادههايى از مرز تعيسين شده براى كلاس خود تجاوز كنند و در محدوده كـلاس ديخـر قرار كيرند. اخر فرض كنيم اين ميزان تخطى برابـر ظ باشـد، در اين صورت مسئله بهينـهسـازى تبــيل مسىشـود بـهـ يـافتن بلنحوى كه معادله زير مينيمم شود. 


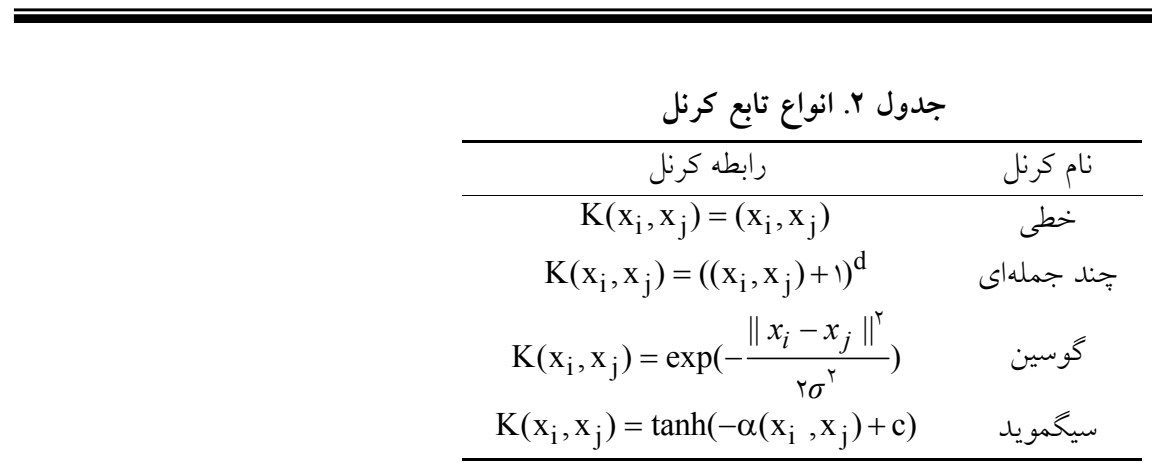

\section{جدول r. تركيبات مختلف ورودى به مدل SVM}

\begin{tabular}{|c|c|c|c|}
\hline $\mathrm{Fr}, \theta, \mathrm{h} / \mathrm{w}, \mathrm{L} / \mathrm{B}$ & تركيبV & $\mathrm{L} / \mathrm{B}, \mathrm{h} / \mathrm{w}$ & تركيبا \\
\hline We, $\theta, \mathrm{h} / \mathrm{w}, \mathrm{L} / \mathrm{B}$ & تركيب1 & $\mathrm{h} / \mathrm{w}, \theta$ & تركيبr \\
\hline $\mathrm{Re}, \theta, \mathrm{h} / \mathrm{w}, \mathrm{L} / \mathrm{B}$ & تركيب9 & $\mathrm{L} / \mathrm{B}, \mathrm{h} / \mathrm{w}, \theta$ & تركيبr \\
\hline $\mathrm{Re}, \mathrm{We}, \mathrm{Fr}, \theta, \mathrm{h} / \mathrm{w}$ & تركيبه & Fr, $\theta$ & تركيب \\
\hline $\mathrm{We}, \mathrm{Fr}, \theta, \mathrm{h} / \mathrm{w}, \mathrm{L} / \mathrm{B}$ & تركيب|| & Fr, $\theta, \mathrm{h} / \mathrm{w}$ & تركيبه \\
\hline $\mathrm{Re}, \mathrm{We}, \mathrm{Fr}, \theta, \mathrm{h} / \mathrm{w}, \mathrm{L} / \mathrm{B}$ & تركيبr| & $\mathrm{h} / \mathrm{w}, \theta, \mathrm{We}$ & تركيب9 \\
\hline
\end{tabular}

$\mathrm{MNE}=\frac{1}{\mathrm{~N}} \sum_{\mathrm{i}=1}^{\mathrm{N}}\left|\frac{\mathrm{Cdo}-\mathrm{Cdp}}{\mathrm{Cdo}}\right|$

$R^{r}=\left(\frac{\sum_{i=1}^{N}\left(\mathrm{Cd}_{i}^{o}-\overline{\mathrm{Cd}}^{\mathrm{o}}\right)\left(\mathrm{Cd}_{\mathrm{i}}^{\mathrm{p}}-\overline{\mathrm{Cd}}^{\mathrm{p}}\right)}{\sqrt{\sum_{\mathrm{i}=1}^{\mathrm{N}}\left(\mathrm{Cd}_{\mathrm{i}}^{\mathrm{o}}-\overline{\mathrm{Cd}}^{\mathrm{o}}\right)^{r} \sum_{\mathrm{i}=1}^{\mathrm{N}}\left(\mathrm{Cd}_{\mathrm{i}}^{\mathrm{p}}-\overline{\mathrm{Cd}}^{\mathrm{p}}\right)^{r}}}\right)^{r}$

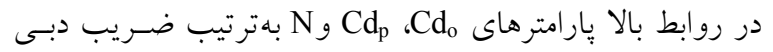

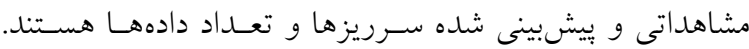

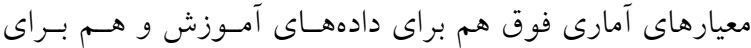
دادههاى آزمون محاسبه مىشوند.

\section{نتايج و بحث}

بلهورى كه در بخش مواد و روشها اشاره شـد، در ايسن تحقيـق

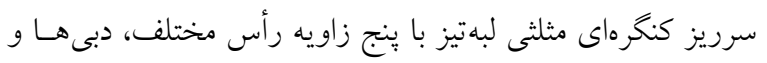
ارتفاعهاى سرريز مختلف در آزمايشگاه مورد بررسى و بـ با سرريز خطى مورد مقايسه قرار گرفته است. براى سـرريزهاى كنخـرهاى

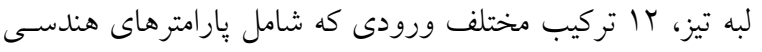

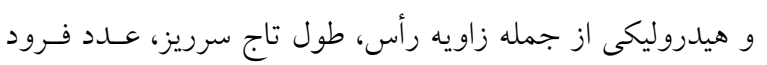

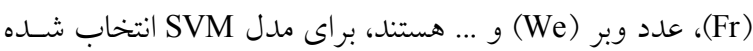

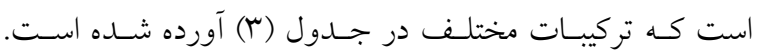
همجنــين بـراى تعيسين ضـرايب دبسى ايـن سـرريزها معـادلات

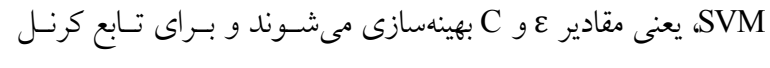
RBF

روند ارزيابى كارايى مدلها به منظور دستيابى به نتايج بيشبينى بهتر و دقيقتر مدلها، روند مدردابـ

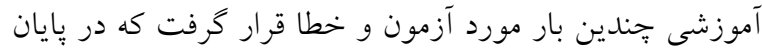

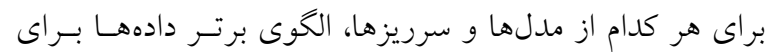

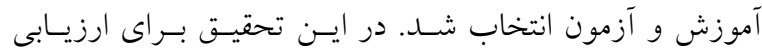

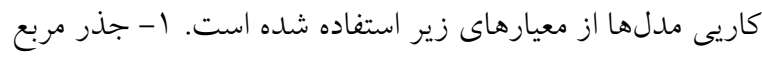

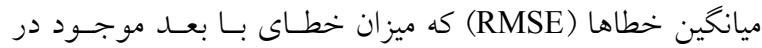

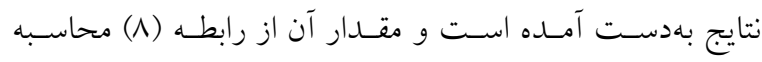

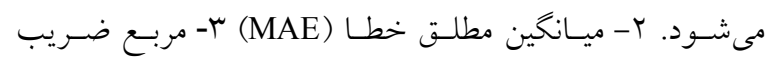

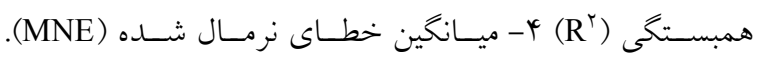

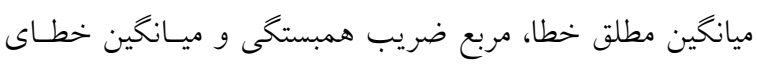

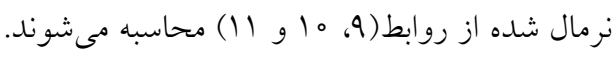

RMSE $=\sqrt{\sum_{i=1}^{N} \frac{(\mathrm{Cdo}-\mathrm{Cdp})^{\wedge} r}{N}}$

$\mathrm{MAE}=\frac{1}{\mathrm{~N}} \sum_{\mathrm{i}=1}^{\mathrm{N}}|\mathrm{Cdo}-\mathrm{Cdp}|$ 
كاربرد سيستمهاى تكاملى در تعيين ضريب دبى سرريزهاى كنگرهاى مثلثى

\begin{tabular}{|c|c|c|c|c|c|c|c|c|c|c|c|}
\hline \multicolumn{4}{|c|}{ يار امترهاى SVM } & \multicolumn{3}{|c|}{ آزمون } & \multicolumn{4}{|c|}{ آموزش } & \multirow[b]{2}{*}{ نام تر كيب } \\
\hline$\gamma$ & $\varepsilon$ & $\mathrm{C}$ & MNE & MAE & RMSE & $\mathrm{R}^{r}$ & MNE & MAE & RMSE & $\mathrm{R}^{r}$ & \\
\hline$T / D$ & $\circ / 0$ & 100 & $0 / 040$ & $0 / 0 Y 9$ & $0 / 049$ & $\circ / \Lambda \circ Y^{t}$ & ०/०Mा & O/OYI & $0 / 0 \psi^{4}$ & $\circ / \Lambda V I$ & تركيبl \\
\hline$r$ & $0 / 0$ & 10 & O/OYY & $0 / 019$ & \% TQI & $\circ / 191$ & $0 / 0 Y_{0}$ & $0 / 014$ & $0 / 0 Y 1$ & $\circ / 9 \circ V$ & تركيبr \\
\hline$r$ & 1 & 10 & $0 / 01 V$ & $0 / 011 Y$ &.$/ 0111$ & $0 / 9 V^{4}$ & $0 / 01 \mu_{0}$ &.$/ 0094$ & $0 / 0110$ & $0 / 9 V 9$ & تركيبr \\
\hline$r$ & 1 & 10 & $0 / 0 r q$ & سM/0 & $0 / 001$ & $\circ / \Lambda \circ H$ & ./०सG & ०/०TQ & .040 & - ATG & تركيب \\
\hline r & 1 & 100 & $\circ / 0 Y \Lambda$ & $0 / 019$ & $0 / 0 T V$ & -/^q4 & O०YY & $0 / 01 Y$ & $0 / 0 Y_{0}$ & $0 / 911$ & تركيبه \\
\hline$r / D$ & 1 & 100 & ס/0rt & $0 / 0 Y 1$ & $0 / 0 Y 9$ & $\circ / \wedge \wedge \vee$ & O/OYY & $0 / 014$ & $0 / 0 Y_{0}$ & $\circ / 9 \circ Y$ & تركيب9 \\
\hline 0 & 10 & 10 & $.01 \mathrm{VI}$ & $0 / 019$ & ००YI० & $0 / 991$ & $0 / 01 \mu$ & $0 / 010$ &.$/ 01 \wedge 1$ &.$/ 990$ & تركيبV \\
\hline 0 & 10 & 10 &.$/ 010 \wedge$ &.$/ 010 \mathrm{~V}$ & $0 / 010$ & $0 / 994$ & $0 / 0149$ & $0 / 010$ & $0 / 0110$ & $0 / 99 \mathrm{~V}$ & تركيب^ \\
\hline$r$ & $\circ / 0$ & 10 & ०/OYYO &.$/ 0109$ & $0 / 0 Y_{0}$ & $0 / 919$ &.$/ 011$ & $0 / 01 r$ & ०० Y II &.$/ 9 \mu^{4}$ & تركيب9 \\
\hline$r / 0$ & $\circ / 0$ & 10 & ס/OYMI & $0 / 014 \wedge$ &.$/ 0 T Q$ & $0 / 199$ & ०/०Y० & $0 / 01$ N & /OYTO & $0 / 911$ & تركيبه \\
\hline$r / 0$ & $\circ / 0$ & 100 &.$/ 01 V 0$ & $0 / 01 k t$ &.$/ 0194$ & $0 / 940$ & $0 / 014 q$ & .01111 & $0 / 0110$ &.$/ 990$ & تركيب|| \\
\hline 0 & $\circ / 0$ & 100 & .0194 & $0 / 014 q$ & .0191 & $0 / 949$ & .0194 & .01111 & $0 / 0 Y_{0} 1$ & $0 / 901$ & تركيب | \\
\hline
\end{tabular}
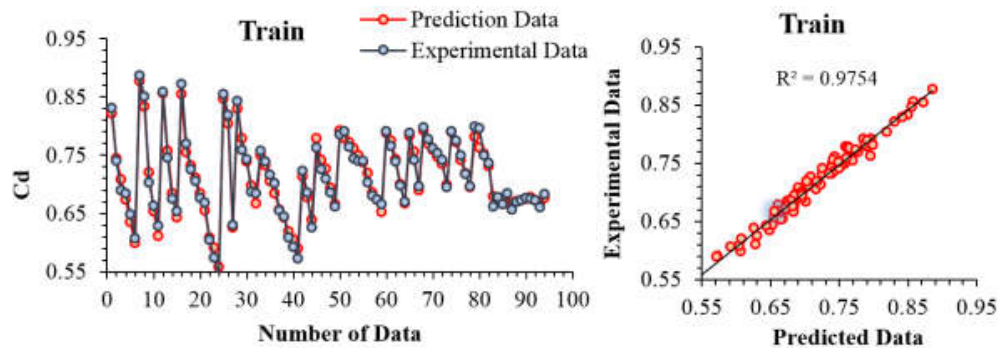

شكل r. مقايسه ضريب دبى آزمايشگاهى و بيشبينى شده در مرحله آموزش (تركيب برتر)

جدول (Y) مشخص است بعد از تركيـب شـماره (Y)، تركيـب

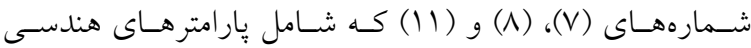
مذكور و يارامترهاى هيدروليكى (Fr و We) هسـتند نيـز داراى نتايج نسبتاً خوب و نزديك به هــم هستـند ولـى نتـايج آنهـا از تركيب شماره (r) نسبتاً ضعيفتــر هسـتند. نمـودار بــر اكنش و تغييرات ضريب دبى براى تركيب شماره (r) (تركيب برتسر) در

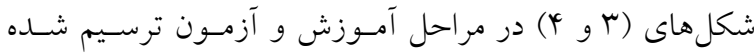
است. با دقت در اين نمودار مشخص مىشود كه ضرايب دبسى مشاهداتى و آزمايشخاهى سرريزهاى كنخرهاى مثلثى لبه تيـز در مرحله آموزش و آزمون با دقت بالايى بيشبينى شده و انطبـاق خوبى با دادههاى آزمايشخاهى داشته و داراى ضريب همبستخى بسيار بالايى هستند كه مىتوان جنـين نتيجـه كرفـت كـه مــل دVM
ركرسيونى خطى و غيرخطى ارائه شده و درنهايت بهازاى زواياى مختلف رأسها، و بر اساس معادله ريبـوى (YV) نيـز معـادلات مربوطه ارائه شد و با روش هاى ماشين بردار يشتيبان و كومـور و همكاران (Y) مورد مقايسه قرار گرفته است. نتايج ماشين بردار يشتيبان در يِيشبينى ضريب دبى در جدول (Y)، Y| أركيب مختف ورودى به همـراه معيارهـاى

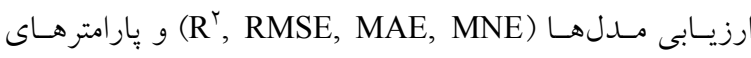
بهينه شده ماشين بردار يشتيبان (c, E, ) آورده شـده اسـت. در ماشين بـردار يشـتيبان (SVM)، تركيـب شـماره (T) كـه فقط شامل پِار امترهاى هندسى (O, h/w, L/B) اسـت، داراى بهتـرين و در مرحله آزمون دادهها است. بهطورى كـه در 

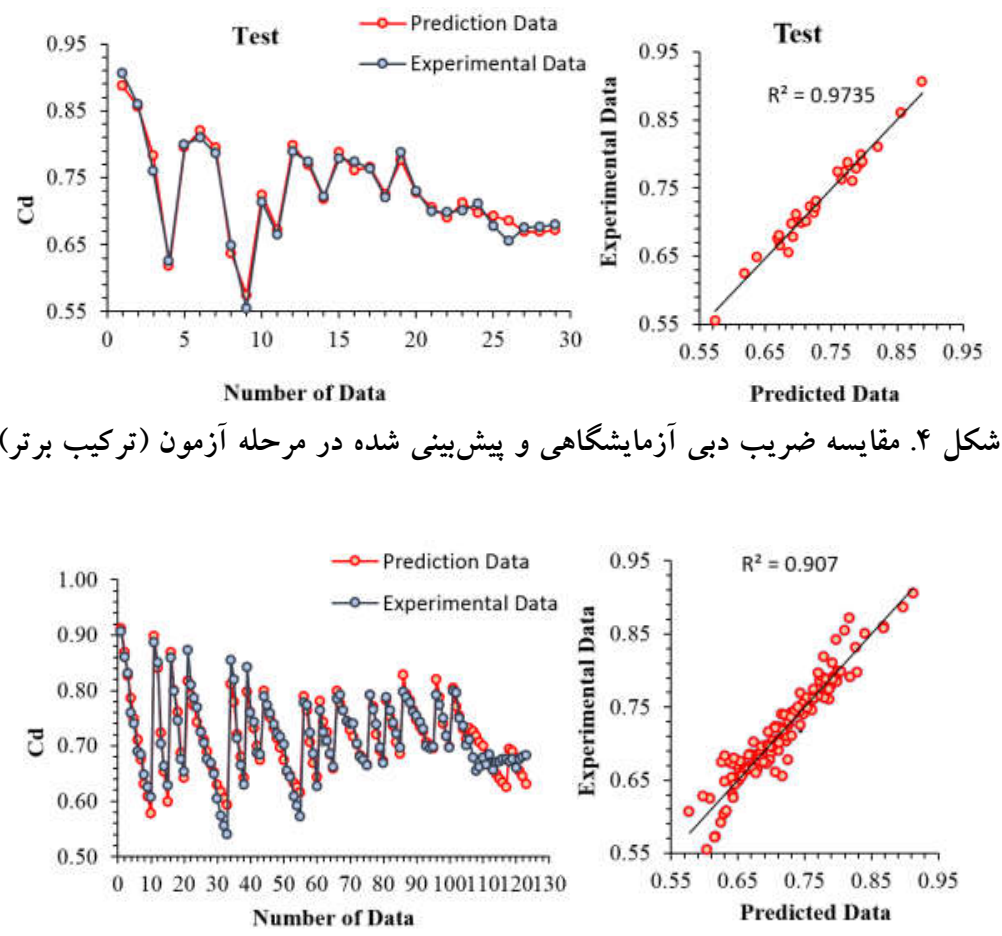

شكل ه. مقايسه ضريب دبى آزمايشگاهى و بيشبينى شده توسط معادله غيرخطى
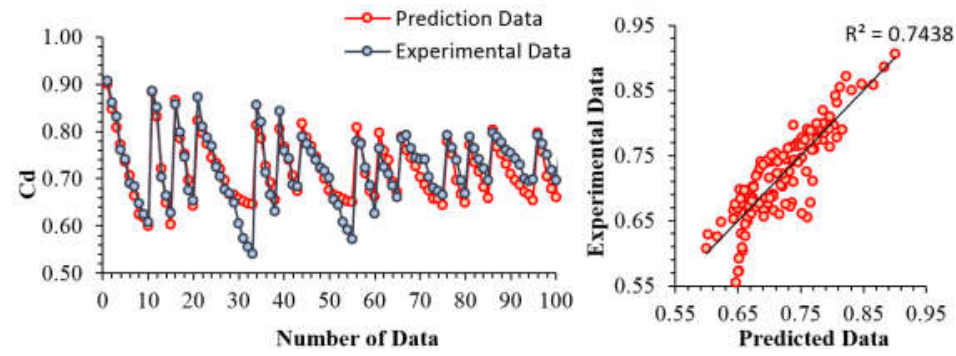

شكل 9. مقايسه ضريب دبى آزمايشگاهى و بيش بينى شده توسط معادله خطى

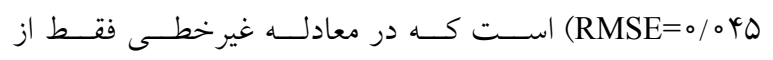

يارامترهاى هندسى استفاده شد ولى در معادله خطى عـاوه بــر

يارامترهاى هندسى، يار امتر بدون بعد عدد فرود نيز وارد معادله

شده است. در شكلهاى (ه و 9) نمـودار بـــراكنش و تغييـرات

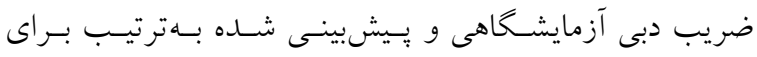

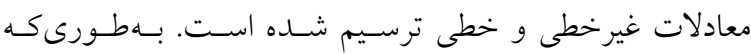
مشاهده مىشود، مقادير ضريب دبى هـيشبينسى شـده در روش

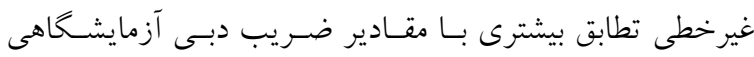
نسبت به روش خطى دارد. همجنين بهطورى كه در هر دو روش
لبه تيز عملكرد بسيار خوبى از خود نشان مىدهد.

معادلات خطى و غيرخطى در يِشبينى ضريب دبى در تحقيق حاضر معادلات رگرسـيون غيرخطى و خطسى جنـد جملهاى براى دادههاى آزمايشخاهى ارائه شده است كه ضسريب دبى سرريزهاى كنخرهاى مثلثى لبه تيز بـهـــورت غيرخطى و

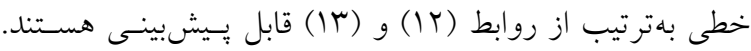

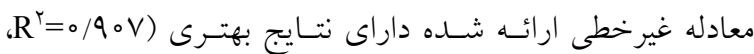

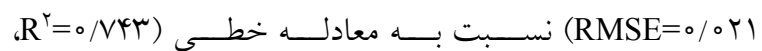


كاربرد سيستمهاى تكاملى در تعيين ضريب دبى سرريزهاى كنخرهاى مثلثى

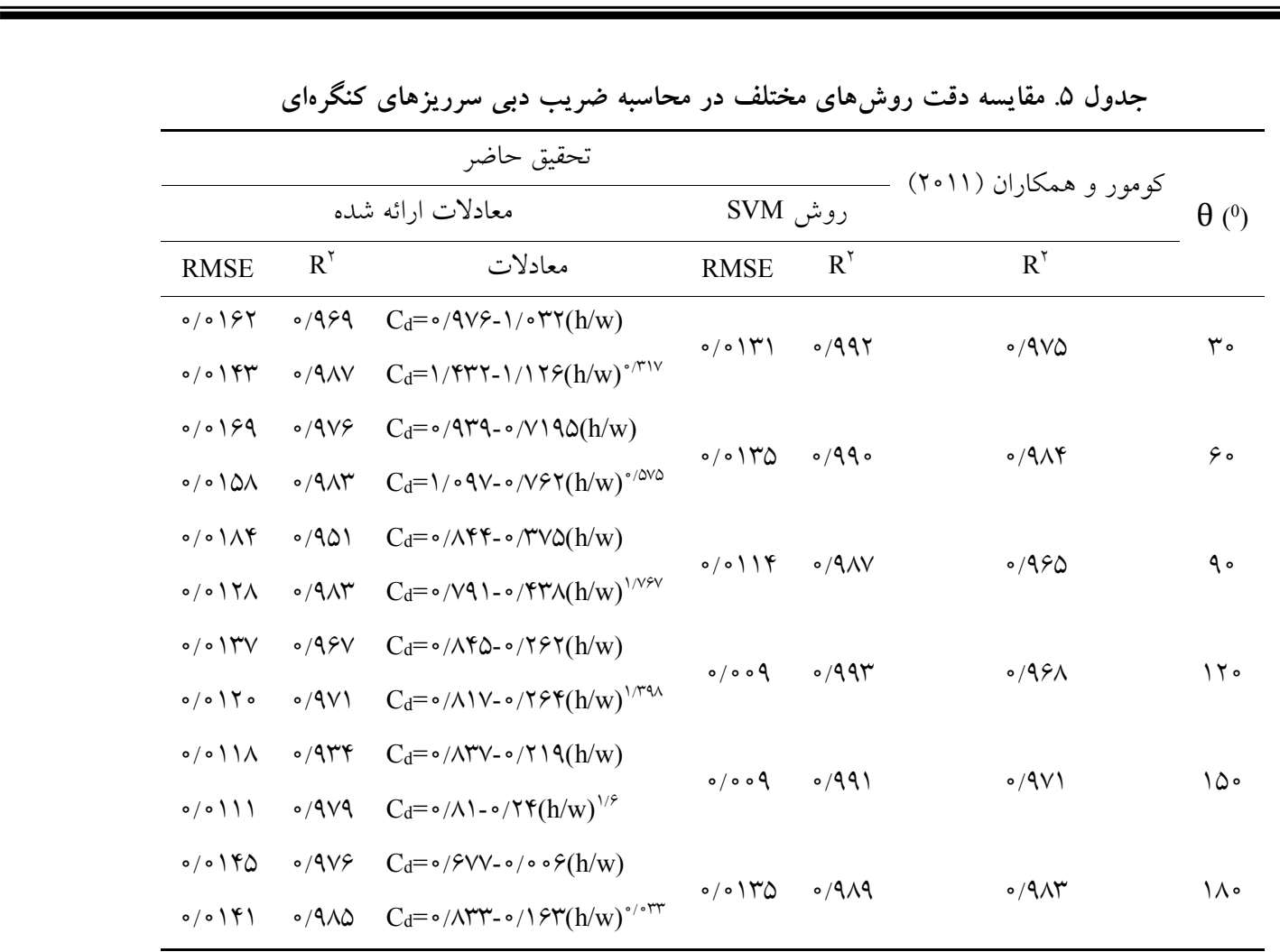

معادله ريبوك استفاده شـده اسـت و در ادامسه از روش ماشـين بردار يشتيبان (SVM) براى بيشبينى ضريب دبى اين سـرريزها و بر اساس معادله ريبـوك اسـتفاده شــه و بــا روش كومـور و همكاران ( (Y) مورد مقايسه قـرار كرفتـهانـد. بـهـــورى كـه در جدول (ه) مشخص است براى محاسبه ضريب دبى سرريزهاى كنخرهاى با زواياى رأس مختلف، روش SVM، روش غيرخطى، روش كومور و همكاران و روش خطى بهترتيب بهترين نتايج را

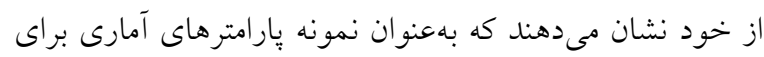
زاويـــا اس R R

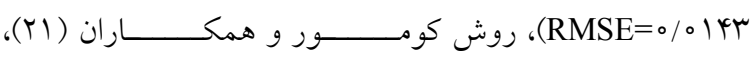
$\left(\mathrm{RMSE}=0 / 019 r ، \mathrm{R}^{r}=0 / 999\right)\left(\mathrm{R}^{r}=0 / 9 \mathrm{VQ}\right)$ بهدست آمده است.

\section{تتيجه كيرى}

در اين تحقيق قابليت عملكرد روش ماشين بردار بشتيبان بـراى
مشخص است، بيشترين اختلاف ضريب دبى در مقادير ماكزيمم و مينيمم مشاهده مىشود كه نشاندهنده يُايين بودن دقـت ايـن معادلات در نقـاط مـذكور اسـت در حـالىكـه در سـاير نقـاط بيشبينى اين روشها داراى دقت مناسبى هستند. $\mathrm{Cd}=\left(-\circ / \circ v^{\prime} \Delta \theta^{r}+\circ / \operatorname{cor} \theta^{r}-\circ / \operatorname{ar\Delta } \theta+1 / \Delta r \Lambda\right)+$

$$
\begin{aligned}
& \left(-0 / \operatorname{rgr}(\mathrm{h} / \mathrm{W})^{r}+1 / \operatorname{lrr}(\mathrm{h} / \mathrm{W})^{r}-1 / 111\right. \\
& (\mathrm{h} / \mathrm{W})-0 / \mathrm{Irr})+0 / \mathrm{r} \mid 9 \wedge(\mathrm{L} / \mathrm{B}) \\
& \mathrm{Cd}=\circ / \wedge \mathrm{r}-\circ / \circ \circ 9 \theta+\circ / \circ \Delta \Lambda \mathrm{h} / \mathrm{W}+ \\
& . / 0 \% v L / \mathrm{B}^{-1 / \mu} \mathrm{Fr}
\end{aligned}
$$

تعيين ضريب دبسى سـرريزهاى كنخــرهاى بـر اســاس روش

Rehbock در اين بخش از تحقيق ضريب دبى سرريزهاى كنخرهاى لبهتيـز براى زوايـاى مختلـف رأسهـا و بـر اسـاس معادلـه ريبـوى، براي (Cd=a+b (h/w) Rehbock بيشبينى با دقـت بيشـتر از تـوان غيرخطى قِّارامتر (h/w) در 
در مرحله آزمون دادهها اسـت. بـا توجسه بــه

نتايج بهدست آمده، مقادير ضريب دبى بيشبينى شده در معادله

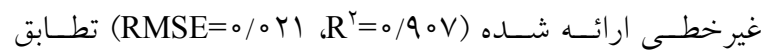
بيشترى با مقادير ضريب دبى آزمايشـگاهى نسـبت بـه معادلـه

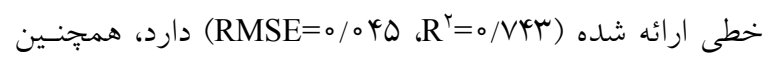
بهطورى كه در هر دو روش مشخص اسـت، بيشـترين اخـتلاف ضريب دبى در نقاط عطف مشاهده مىشود، درحالى كه در ساير نقاط يِيشبينى اين روش ها داراى دقـت بـالايى هسـتند. بـراى محاسبه ضريب دبى سرريزهاى كنكرهاى لبـهـيـز و بــا زوايـاى رأس مختلف و بر اساس معادله ريبوك بهترتيـب روش SVM، روش غيرخطى، روش كومور و همكاران و روش خطى بهترين نتايج را از خود نشان مىدهند. بهطوركلى مىتوان نتيجه كرفت

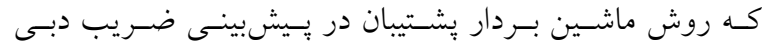
سرريزهاى كنخرماى لبه تيـز عملكـرد بسـيار مناسـبى داشـته و مىتوان از اين روش در شرايط مشابه استفاده كرد.
يِيشبينى ضريب دبى سرريزهاى كنخرهاى مثلثى لبه تيـز مـورد بررسى قرار كرفت، همجهنـين بـراى تعيسين ضـرايب دبسى ايسن سرريزها معادلات رگرسيونى خطى و غيرخطى ارائه شـده و در

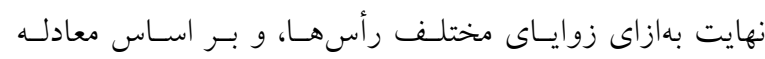
ريبوك، معادلات مربوطه ارائه شد و با روشهاى ماشين بـردار يشتيبان و كومور و همكاران (Yll) مورد مقايسه قرار كرفت كـه در اين راستا در مجموع از بrا سرى داده آزمايشـاهى بـراى بررسى نتايج استفاده و بهمنظور ارزيابى كارايى مدلها و مقايسه

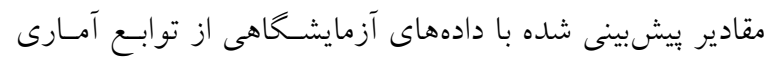

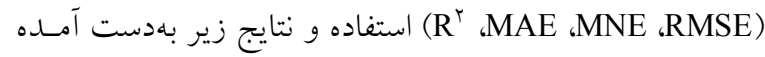
است. ماشين بردار بشتيبان (SVM)، در بيشبينى ضـريب دبسى سرريزهاى كنخرهاى مثلثى لبه تيز عملكرد بسيار خوبى از خــود

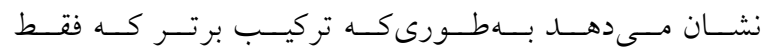

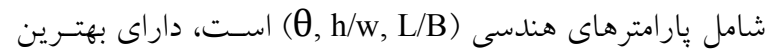
و

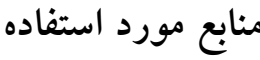

ا. جاويد، ا.، م. موسى خانى. الوبا. مديريت كيفى مخازن سدها با استفاده از مدل ماشـين بـردار بشـتيبان، ششـمين همـايش ملى مهندسى محيط زيست. تهران.

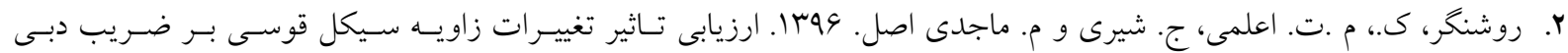

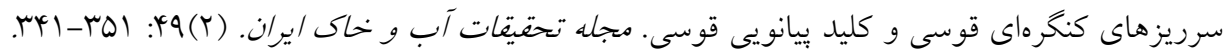
r. زاهدى خامنه، ح. اوسا. مطالعه تأثير تغيير هندسه سرريز و افزايش تعداد سيكل بر ضريب تخليه سرريزهـاى جـانبى منقـارى و نيمدايرهاى. ياياننامه كارشناسى ارشد، دانشخاه فردوسى مشهد، مشهد.

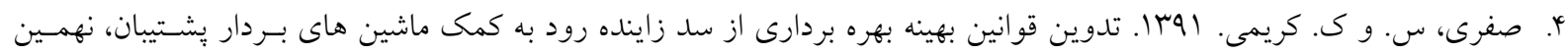
كنكره بين المللى مهندسى عمران. اصفهان.

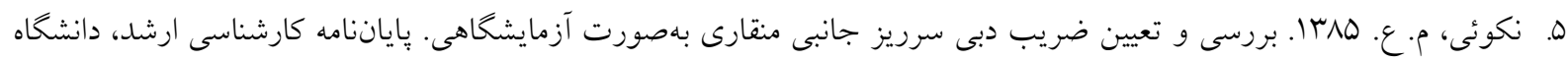
صنعتى شريف، تهران، ايران.

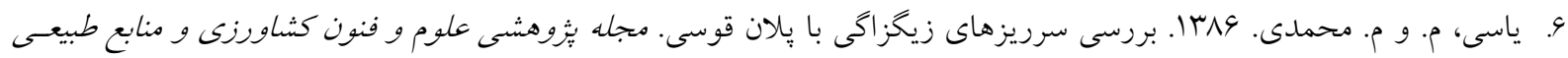
$.1-11:(4) 11$

7. Behzad, M. and K. Asghari. 2008. Generalization performance of Support vector machines and neural networks in run off modeling. Expert Systems with Applications 36(4): 7624-7629.

8. Borghei, M., M. R. Jalili and M. Ghodsian. 1999 Discharge coefficient for sharp-crested side weir in subcritical flow. Journal of Hydraulic Engineering 125(10):1051-1056.

9. Çimen, M. 2008. Estimation of daily suspended sediments using support vector machines. Hydrological Sciences 
Journal 53(3): 656-666.

10. Christensen, N. A. 2012. Flow characteristics of arced labyrinth weirs. MSc. Thesis, Utah State University, Logan, UT.

11. Darvas, L. A. 1971. Performance and design of labyrinth weirs. Journal of Hydraulic Engineering 97(8): 1246-1251.

12. Emiroglu, M. E., O. Kisi and O. Bilhan. 2010. Predicting discharge capacity of triangular labyrinth side weir located on a straight channel by using an adaptive neuro-fuzzy technique. Advances in Engineering Software 41(2): 154-160.

13. Ersayin, D. 2006. Studying Seepage in a Body of Earth-Fill Dam by (Artificial Neural Network) ANNs, Department of Civil Engineering Izmir Institute of Technology. Dissertation of Master of Science, Department of Civil Engineering Izmir Institute of Technology. Turkey.

14. Falvey, H. T. 2003. Hydraulic Design of Labyrinth Weirs. ASCE Press. Pub., Virginia, USA.

15. Gentilini, B. 1940. Stramazzi Con Cresta a Planta Obliqua e a Zig-zag. Memorie Studi dell Instituto di Idraulica e Construzioni Idrauliche del Regil Politecnico di Milano. (In Italian).

16. Goel, A. 2014. Neural network technique for prediction of discharge coefficient and discharge for a weir. Journal of Indian Water Resources Society 34(2): 25-31.

17. Hay, N. and G. Taylor. 1970. Performance and design of labyrinth weirs. Journal of Hydraulic Engineering 96(11): 2337-2357.

18. Henderson, F. M. 1966 Open Channel Flow. Macmillan, New York, USA.

19. Juma, I. A., H. H. Hussein and M. AL-Sarraj. Analysis of hydraulic characteristics for hollow semi-circular weirs using artificial neural networks. Flow Measurement and Instrumentation 38: 49-53.

20. Jie, L. C. and S. T. Yu. 2011. Suspended sediment load estimate using support vector machines on Kaoping River basin. In: Proceeding of the International Conference on Consumer Electronics, Communications and Networks (IEEE), XianNing, China.

21. Kumar, S., Z. Ahmad, T. Mansoor. 2011. A new approach to improve the discharging capacity of sharp-crested triangular plan form weirs, Flow Measurment and Instrumentation 22: 175-180.

22. Lux, F. 1993. Design Methodologies for Labyrinth Weirs. In: Proceeding of the Internatioinal Conference on Hydropower, Water Power Nashville, Tennessee, USA. PP. 1379-1407.

23. Lux, F. and D. Hinchcliff. 1985 Design and construction of labyrinth spillways. In: Proceeding of the $15^{\text {th }}$ Congress ICOLD, Vol. IV, Q59-R15, Lausanne, Switzerland. pp. 249-274.

24. Roushangar, K., M. T.Alami, J. Shiri and M. Majedi Asl. 2017. Determining discharge coefcient of labyrinth and arced labyrinth weirs using support vector machine. Journal of Hydrology Research 924-938.

25. Roushangar, K., M. T. Alami, M. Majedi Asl and J. Shiri. 2017. Modeling discharge coefficient of normal and inverted orientation labyrinth weirs using machine learning techniques. ISH Journal of Hydraulic Engineering 331-340.

26. Roushangar, K., S. Akhgar, F. Salmasi, J. Shiri. 2014. Modeling energy dissipation over stepped pillways using machine learning approaches. Journal of Hydrology 508: 254-265.

27. Rehbock T., Discussion of precise weir measurement. In: E. W. Schoder and K. B. Turner (Ed.), Journal of Transportation Engineering 93: 1143 - 1162.

28. Siviapragasam, C. and S. Liong. 2001. Rainfall and runoff forcasting with SSA-SVM approach, Journal of Hydroinformation 3: 141-152.

29. Taylor, G. 1968. The performance of labyrinth weirs. PhD. Thesis. University of Nottingham, Nottingham, England.

30. Tullis, P., N. Amanian and D. Waldron. 1995. Design of labyrinth weir spillways. Journal of Hydraulic Engineering 121(3): 247- 255.

31. Vapnik, V. 1995. The Nature of Statistical Learning Theory, Data Mining and Knowledge Discovery, PP. 1-47. Springer-Verlag New York, Inc., New York.

32. Zahedi Khameneh, H., S. R. Khodashenas and K. Esmaili. 2014. The Effect of Semi-circular side weirs on hydraulic properties and discharge coefficient of side weirs. Journal of River Engineering 2(5). 5-9. 


\title{
Application of the Evolutionary Methods in Determining the Discharge Coefficient of Triangular Labyrinth Weirs
}

\author{
M. Majedi AsI ${ }^{1 *}$ and M. Fuladipanah²
}

(Received: October 5-2017 ; Accepted: March 4-2018)

\begin{abstract}
A labyrinth weir is a nonlinear weir folded in the plan-view which increases the crest length and the flow rate for a given channel width and an upstream flow depth. Nowadays, a labyrinth weir is an attractive alternative for those weirs that have a problem in passing the probable maximum flood. The three-dimensional flow pattern and unlimited geometric parameters provide a major challenge to the designers of these weirs. The present study aimed at determining discharge coefficients of sharp-crested triangular labyrinth weirs using the support vector machine (SVM). The results were compared with the experimental data. For this purpose, 123 laboratory test data including geometric and hydraulic parameters such as vertex angle $(\theta)$, magnification ratio (L/B), head water ratio $(\mathrm{h} / \mathrm{w})$, Froude number (Fr), Weber Number (We) and Reynolds number $(\mathrm{Re})$ were used. The results showed that the SVM-based model produced the most accurate results when only three geometric parameters, e.g. $(\mathrm{h} / \mathrm{w}, \theta, \mathrm{L} / \mathrm{B})$, were introduced as the input parameters $\left(\mathrm{R}^{2}=\right.$ 0.974 , Root mean square error $[\mathrm{RMSE}]=0.0118$, mean absolute error $[\mathrm{MAE}]=0.0112$ and mean normal error $[\mathrm{MNE}]$ $=0.017$ for the test stage). Also, for these weirs, polynomials linear and nonlinear regression equations were presented. Finally, the discharge coefficient of sharp-crested triangular labyrinth weirs based on the Rehbock equation was evaluated and compared with the SVM using nonlinear and linear regression methods.
\end{abstract}

Keywords: Triangular Labyrinth Weir, Support Vector Machine, Rehbock Equation, Vortex Angle

1. Department of Civil Engineering, Faculty of Engineering, University of Maragheh, Maragheh, Iran.

2. Department of Civil Engineering, Ramhormoz Branch, Islamic Azad University, Ramhormoz, Iran.

*: Corresponding Author, Email: Mehdi.majedi@gmail.com 